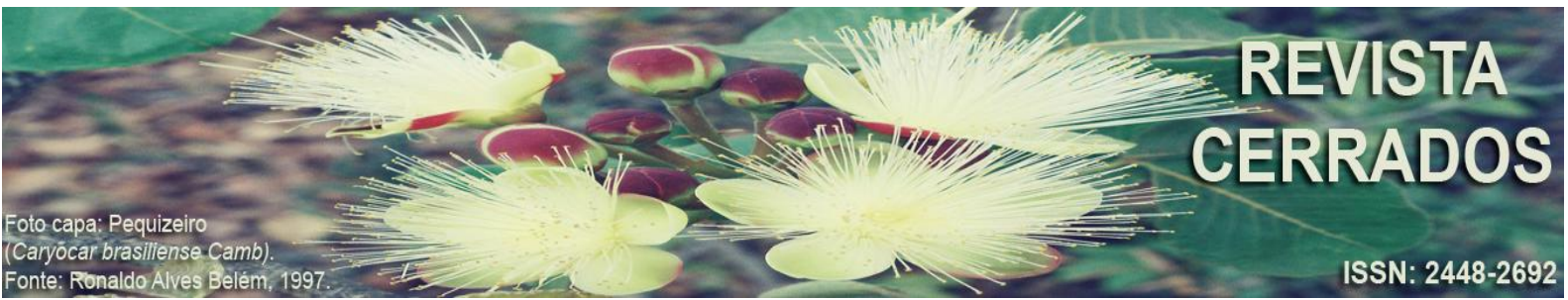

\title{
CENTRO E CENTRALIDADE EM ARAGUAÍNA: reflexão preliminares a partir dos serviços e do comércio em rede ${ }^{1}$
}

\section{CENTER AND CENTRALITY IN ARAGUAÍNA: preliminary reflection from services and network commerce}

\section{CENTRO Y CENTRALIDAD EN ARAGUAÍNA: reflexión preliminar de los servicios y el comercio em rede}

\author{
Reges Sodré \\ Universidade Federal de Uberlândia - UFU \\ E-mail: <regessodre@gmail.com>.
}

\begin{abstract}
Resumo
Este artigo tem por objetivo identificar e analisar o centro da cidade de Araguaína-TO a partir da dimensão econômica, tendo como variáveis o comércio e os serviços. O trabalho elegeu o comércio de eletrodoméstico e de supermercado/atacado, e os serviços bancários, dos correios, das lotéricas e cartórios como atividades chaves para a qualificação do centro e das centralidades. Para a delimitação do centro da cidade de Araguaína considerou-se as ruas e trechos que apresentam concentração de atividades comerciais e serviços acima de $70 \%$, desde que fosse marcado pela contiguidade. Constatou-se dois processos em cursos que consolidam tendências enquanto anunciam outras; primeiro, o centro da cidade de Araguaína tem se fortalecido nos últimos anos pela instalação de grandes empresas, como as casas Bahia e uma agência bancária do Bradesco; segundo, vê-se que diversas empresas que já atuam no centro abrem filias em outras áreas da cidade, outras se instalam diretamente fora do mesmo, como é o caso das lojas americanas, com duas unidades na cidade. Esse quadro permitiu afirmar que as transformações na estrutura urbana ligada ao consumo condizem com uma reestruturação da cidade, pois as mudanças são predominantes.
\end{abstract}

Palavras-chave: Araguaína; centro; restruturação; cidade.

\section{Abstract}

This article aims to identify and analyze the urban center of Araguaína-TO from the economic dimension, having as variables the commerce and the services. The work chose the home appliance and asupermarket/wholesale trade, and banking, post office, lottery and registry offices as key

\footnotetext{
${ }^{1}$ Um esboço desse artigo foi apresentado na disciplina "Comércio e estrutura da cidade" (2015/2) no Programa de Pós-Graduação em Geografia da Universidade Federal de Uberlândia.
} 
SODRE, R.

Centro e centralidade em Araguaína: reflexão preliminares a partir dos serviços e do comércio em rede

activities for the qualification of the center and centralities. For the delimitation of the center of the city of Araguaína was considered the streets and stretches that show concentration of commercial activities and services over 70\%, provided it was marked by the contiguity. There were two processes in courses that consolidate trends while announcing others; first, the Araguaína center has been strengthened in recente years by the installation of large companies, susch as the Bahia houses and a Bradesco Banch; second, it is seen that several companies that already work in the center open branches in other áreas of the city others settle directly outside the same, as is the case of Lojas Americanas, whith two units in the city. This framework allowed us to affirm that the changes in the urban structure linked to consumption are consistente with a restructuring of the city, since the changes are predominant.

Keys-word: Araguaína; center; restructuring; city.

\section{Resumen}

Este artículo tiene como objetivo identificar y analizar el centro urbano de Araguaína en la dimensión económica, con el comercio y los serviços. El aparato de trabajo elegidos comercio y supermercado e los bancos, los correos, las lotéricas y los registros, como actividades clave para la calificación del centro y centralidades. Para definir el centro de Araguaína considera las calles y pasajes que la concentración presente de actividades y servicios comerciales de hasta $70 \%$ desde que fue marcado por contiguidad. Se encontraron dos casos em los cursos que consolidan las tendências de la publicidade mientras que otras; en primer lugar el centro de Araguaína se ha fortalecido en los últimos años por la instalación de grandes empresas, como las casas Bahia e um Bando do Bradesco; em segundo lugar, vemos que muchas empresas que ya operan en el centro filiales abiertas en outras zonas de la ciudad, otros se instalan directamente fuera de el centro, como es el caso de las Lojas Americanas, com dos unidades em la ciudad. Ese marco nos permitió afirmar que los cambios em la estructura urbana asociados com su consumo son consistentes com la reestructuración de la ciudad, debido a que los cambios son frecuentes.

Palabras-clave: Araguaína, centro, reestructuración, ciudad.

\section{INTRODUÇÃO}

Araguaína, com população estimada em 170 mil para 2015 (IBGE, 2015), tem passado por um importante processo de crescimento econômico e melhoria das condições sociais desde 1990. O Produto Interno Bruto a preços correntes saiu de 350 mil em 1999 para atingir em 2012 a cifra de 2,2 milhões. O Índice de Desenvolvimento Humano Municipal passou de 0,451 em 1990 para 0,752 em 2010. O Índice de Gini era em 1991 de 0,62 enquanto em 2010 alcançou 0,56, traduzindo na redução dos pobres de 43,36\% para 11,18\% (BRASIL, ca. 2013). Essa realidade foi acompanhada pelo aumento do mercado de trabalho formal, que empregava em 1990 apenas 5.725 pessoas, atingindo 25.005 em 2010 e um pouco mais de 30 mil em 2014 (RAIS, ca. 2015). Isso não significa que as desigualdades foram 
SODRE, R.

Centro e centralidade em Araguaína: reflexão preliminares a partir dos serviços e do comércio em rede

extintas, pois $61,01 \%$ da população se apropriam apenas de $25,00 \%$ da renda gerada (BRASIL, 2013).

Tais dinâmicas conduzem e alicerçam um processo de urbanização mais robusto (para o contexto do Tocantins), manifesto na crescente instalação de empresas nacionais e internacionais na cidade; no aumento dos serviços, sejam eles públicos ou privados; no crescimento e expansão de empresas locais, que passam a explorar o mercado regional; expansão do tecido urbano; ampliação dos papéis e funções urbanas; aprofundamento das interações e articulações espaciais e surgimento de novos produtos imobiliários, como condomínios fechados e prédios residenciais.

Com isso, diversas transformações e dinâmicas foram impostas ao centro da cidade e a centralidade tornou-se mais complexa. O centro fortaleceu seus papéis, na medida em que aí se instalou um conjunto de bens e serviços, mas paradoxalmente deixou de ser o local exclusivo de consumo e realização da vida econômica na cidade, em razão do surgimento de novos espaços de concentração de bens e serviços, que acompanham e fortalecem o processo de reestruturação da cidade, inclusive com a consolidação de um subcentro no Bairro Senador, junto a Avenida Prefeito João de Souza Lima. Assim, não somente a localização dos agentes comerciais e dos serviços foi redefinida, mas muitas novas práticas espaciais são colocadas em curso.

Diante desse contexto e visando contribuir com a discussão da temática em Araguaína, esse artigo tem por objetivo identificar e analisar o centro dessa cidade a partir da dimensão econômica, tendo como variáveis o comércio e os serviços. Baseado nas metodologias de Ribeiro Filho (2002), Murphy e Vance (1954) e Pereira (2014), delimitou-se o centro comercial e a espacialização dos estabelecimentos comerciais em rede ${ }^{2}$, entre os quais, os de eletrodomésticos e supermercados/atacados. No âmbito dos serviços, estão às agências bancárias (incluindo os PAE e PAB), correios, cartórios e as lotéricas. O texto está organizado da seguinte maneira: primeiro levanta-se alguns aspectos conceituais da questão do centro e da centralidade para em seguida arvorarmos os resultados da pesquisa.

\footnotetext{
${ }^{2}$ Estabelecimentos comerciais em rede são aqueles que tem mais de uma unidade em Araguaína e/ou em outras cidades.
} 


\section{Uma reflexão sobre o centro da cidade e a centralidade}

De início, esclarece-se que seguindo as orientações de Castells (2014) sobre a necessidade de recortes conceituais no estudo dos centros citadinos e os níveis de sua apreensão por ele proposto (econômico, político-institucional e ideológico), nossa preocupação, seja em termos teóricos ou empíricos acerca do centro, se restringe nesse trabalho a sua dimensão econômica, em razão da afinidade do autor com essa temática e da importância por ela adquirida na constituição do centro da cidade em estudo. Isso não implica mutismo a respeito de sua centralidade ligada aos aspectos simbólicos e políticos, até porque em muitos casos essas dimensões são indissociáveis.

Segundo Castells (2014) o centro da cidade tem sido visto em três categorias, integrador e simbólico, que faz as trocas e coordena e, finalmente, como núcleo lúdico. No primeiro aspecto, aparece como elemento fundante da análise a ideia de comunidade urbana, materializada em características que favorecem a comunicação entre as pessoas, a acessibilidade ante a estrutura urbana e divisão interior do espaço central. O centro que $f a z$ trocas e coordena se expressa pela concentração comercial, das atividades administrativas, financeiras e políticas. Tem um caráter funcional, seja pela objetivação da espacialização da divisão técnica e social do trabalho, ou especialização em segmentos de comércio e serviço. Por último, na categoria de núcleo lúdico, o centro se constitui como um espaço do lazer e diversão, mas também como sublimação da vida urbana.

Castells (2014, p. 313) adverte, no entanto, que "nenhuma dessas três categorias de centros, que possuem uma forte carga de expressão concreta, existe por si, mas sim enquanto resultado de um processo social de organização do espaço urbano”. O autor pretende com isso evidenciar que o centro assim como a cidade não são neutros - a-históricos, mas frutos de tensões e lutas sociais que, por vez, expressam suas contradições, tendo como pano de fundo as bases pelas quais se reproduz o sistema capitalista, coexistindo diversas temporalidades e espacialidades, que se complementam e se contradizem.

Segundo Sposito (1991, p. 6)

O centro não está necessariamente no centro geográfico, e nem sempre ocupa o sítio histórico onde essa cidade se originou, ele é antes de tudo ponto de convergência/divergência, é o nó do sistema de circulação, é o lugar para onde todos se dirigem para algumas atividades e, em contrapartida, é o ponto de onde todos se deslocam para a interação destas atividades aí localizadas com as outras que se realizam no interior da cidade ou fora dela. Assim, o centro pode ser qualificado como integrador e dispersor ao mesmo tempo. 
Nesse sentido, o centro da cidade é o local onde a atividade econômica atinge maior densidade, com concentração, centralização e valorização do solo, sendo um elemento fundamental do processo de acumulação e da própria reprodução da sociedade capitalista. Nele é possível encontrar dos mais sofisticados produtos e serviços aos mais comuns e pueris, representado em corporações multinacionais e no mercado informal. É o espaço no qual os ruídos, as cores e a diversidade de encontros e tempos possíveis atinge o pináculo na cidade.

Para Lefebvre (1999, p. 44) “o centro urbano é preenchido até a saturação; ele apodrece ou explode", isto é, o centro contém em si, sua negatividade, sendo uma realidade mutável no tempo. Tal fato pode ser exemplificada com a crescente dimensão adquirida pela urbanização ao longo do tempo, que impõe novas dinâmicas à questão do centro da cidade, como o surgimento de subcentros, eixos comerciais, ruas comerciais, expansão da área central e os shoppings centers (CASTELLS, 2014; SPOSITO, 1991). Esses processos se materializam de forma distinta no espaço em razão dos motivos e finalidades que os orientam, mas todos são frutos das novas formas de localização das atividades econômicas na cidade.

Entre os fatores que podem causar descentralização de atividades centrais do centro (advinda de seu "apodrecimento") e que está diretamente relacionado ao surgimento de novas áreas de centralidade, estão, conforme Corrêa (1979); a) aumento excessivo das despensas com a ocupação do espaço, como o preço da terra, aluguéis, impostos, etc.; b) dificuldades com o transporte em vista do aumento dos congestionamentos e maiores custos com as comunicações; c) escassez de espaço para expansão das atividades; d) restrições legais de controle do espaço; e) pressão contra determinados tipos de usos do solo e perda de amenidades que afetam a população de maior renda. Ainda segundo Corrêa (1979), as áreas procuradas pelos agentes econômicos para fugir desses problemas possuem qualidades opostas a do centro.

De acordo com Sposito (1991, p. 9) a expansão da área central caracteriza-se pela “absorção de áreas/setores limítrofes ao centro, através do afastamento de sua população residencial e a transformação de seu uso de solo em comercial e de serviços"; enquanto os subcentros, que estão localizados geralmente distantes do centro, "são áreas onde se alocam as mesmas atividades do centro principal com diversidade comercial e de serviços, mas em escala menor, e com menor incidência de atividades especializadas” (ibidem, p. 10); já os eixos comerciais são definidos como a "localização de atividades terciárias tipicamente 
centrais [mas de forma especializada], ao longo de vias de maior circulação de veículos" (ibidem, p. 10).

Castells (2014) afirma que assiste-se, no contexto metropolitano, cada vez mais a uma diminuição dos papéis comerciais dos centros, à medida que a cidade se estende, a mobilidade das pessoas aumenta (com o uso do automóvel), e novas formas de comprar pela internet entram em cena. A tendência, segundo ele é que o velho centro se defina cada vez mais pelas suas funções de gestão, informação e mercados populares. Para Sposito (2013) amplia-se, de um lado, o uso do centro nas metrópoles pelo setor informal, de outro, cada vez mais as populações que o frequentam são aquelas que não conseguem visitar cotidianamente os shoppings centers.

Tourinho (2006) argumenta que a centralidade como lugar, rompeu com o discurso urbanista que considerava a centralidade um atributo exclusivo do lugar central, sendo possível o surgimento de centralidade sem Centro. Segundo a autora a centralidade tornou-se independente do Centro, distanciou-se dele, conceitual e fisicamente falando. Em outras palavras, a centralidade pode se expressar em outras áreas fora do Centro principal, como em shoppings centers e eixos comerciais, sem que os mesmos sejam ou se tornem centros, nem estejam a ele hierarquicamente subordinados - todo centro é dotado de centralidade, mas nem toda centralidade se manifesta através de um centro.

Para compreender essas transformações que os centros das cidades vêm sofrendo é fundamental "trabalhar com a articulação entre escalas" (SPOSITO, 2013, p. 46), pois a complexidade do centro e da centralidade está intimamente relacionada ao nível hierárquico da cidade, a situação geográfica, a inserção em aglomerações e as temporalidades que sobre ela atuam (SPOSITO, 2013). Se de um lado, como vimos, o centro das metrópoles vem perdendo importância e assumindo características mais especializadas, o mesmo não se pode dizer de forma generalizada para as cidades médias, o que dirá as cidades pequenas. Essas últimas, aliás, tem seus centros restritos, grosso modo, a uma rua principal, formada em muitos casos pela rodovia estadual ou federal que corta a cidade ${ }^{3}$.

Whitacker (2010), tratando das cidades médias, e reforçando os processos propostos por Sposito (2013), afirma que a presença de empresas multinacionais de atuação no terciário fomenta nessas cidades não apenas o consumo, como permite a constituição de

\footnotetext{
${ }^{3}$ As cidades pequenas são por excelência monocentricas, possuindo estrutura comercial e de serviços claramente identificável em ponto único, a respeito ver Melo (2008).
} 
SODRE, R.

Centro e centralidade em Araguaína: reflexão preliminares a partir dos serviços e do comércio em rede

novas áreas centrais dotadas de conteúdos distintos. Nesse prisma ele destaca que "as redes de lojas e magazines, os hotéis de redes tendem a se localizar em shopping centers e novas áreas centrais periféricas e/ou em eixos, contíguos, ou não ao centro tradicional, ancoradas, ou não, por hipermercados" (WHITACKER (2010, s/p).

Em um esforço de síntese Sposito (2013) aponta dois grupos de cidades médias nas quais as dinâmicas no centro são distintas; o primeiro, formado por cidades que passam por processo de reestruturação da cidade $^{4}$, com a instalação de shopping centers e grandes redes de hipermercados; o segundo grupo, é formado por cidades que vivem um relativo declínio dos papéis urbanos, nelas há ausência dos grandes investimentos, e quando redes de lojas se instalam as escolhas locacionais acabam por reforçar a centralidade do centro.

Em suma, centro e a centralidade como um dos elementos principais da vida urbana estão submetidos a diversos graus de dinamismos em escala espacial e temporal. Desse modo, no esforço de compreendê-los é premente a definição de recortes conceituais e territoriais, sem perder de vistas as múltiplas articulações necessárias a apreensão desses mesmos recortes, incluindo-se o papel do tempo.

\section{Centro e centralidade na cidade de Araguaína: serviços e comércio em rede}

Para a delimitação do centro da cidade de Araguaína considerou-se as ruas e trechos que apresentam concentração de atividades comerciais e serviços acima de $70 \%$, desde que fosse marcada pela contiguidade. Esse procedimento é baseado naqueles elaborados por Ribeiro Filho (2002) e Murphy e Vance (1954), concernente ao uso do solo, e principalmente o adotado por Pereira (2014). Assim como a pesquisa de Pereira (2014), e diferentemente das outras citadas, que delimitaram a área central da cidade, com o seu hard core, zona periférica e zona mista, tem-se aqui apenas o objetivo de delimitar o centro comercial, pois nosso foco está na distribuição das atividades selecionadas pela cidade, que se mostrou suficiente para entender o centro e as dinâmicas na centralidade.

Em termos operacionais utilizou-se de vários instrumentos para o levantamento dos dados, que podem ser divididos em dois momentos. $\mathrm{O}$ primeiro consistiu no acesso as

\footnotetext{
${ }^{4}$ Essa autora vem trabalhando com dois pares: reestruturação da cidade e reestruturação urbana, o primeiro reservado ao plano intra-urbano, enquanto o segundo está mais relacionado a escala interurbana, ainda que possua uma dimensão mais complexa. Quando nesse trabalho for citado o termo reestruturação da cidade, é nessa autora que está baseado.
} 
SODRE, R.

Centro e centralidade em Araguaína: reflexão preliminares a partir dos serviços e do comércio em rede

imagens disponíveis no Google Earth, através de sua ferramenta Street View, do ano de 2012, que possibilitou a quantificação de estabelecimentos por ruas e, por conseguinte, a delimitação do centro. Para efeito de seleção, os trechos de uma rua (quadra) que não possuíssem até $70 \%$ de estabelecimentos comerciais foram desconsiderados. No segundo momento, que viabilizou a localização das lojas em rede e dos serviços, foi usado além de imagens do Street View, acesso a sites de jornais/empresas e visita a campo para identificação e anotações de pontos para levantamento de coordenadas e nome das empresas.

$\mathrm{Na}$ tabela 1 encontram-se as ruas (e seus trechos) que foram consideradas como fazendo parte do centro de Araguaína. Nelas foram contabilizados um total de 513 estabelecimentos comerciais e de serviços; 46 residências e 59 classificados como outros, que inclui unidades não identificadas e lotes vazios. As ruas que possuem maior taxa de uso produtivo são as Ruas Gaúcho (100\%), Rua das Mangueiras (95\%), Rua Dezenove de Novembro (93\%) e Avenida Cônego João Lima (91\%). Os altos índices que apresentam essas primeiras ruas se devem muito em função dos pequenos trechos selecionados, ao contrário da última, que de fato possui grande densidade econômica em todo seu trajeto.

Tabela 1 - Ruas/trechos que fazem parte do centro de Araguaína

\begin{tabular}{|c|c|c|c|c|}
\hline Ruas & Estabelecimentos & Residência & Outros & $\begin{array}{c}\% \text { de } \\
\text { estabelecimentos }\end{array}$ \\
\hline Av. Cônego João Lima & 170 & 4 & 12 & $91 \%$ \\
\hline Av. Primeiro de Janeiro & 77 & 11 & 11 & $78 \%$ \\
\hline Rua Santa Cruz & 21 & 8 & 0 & $72 \%$ \\
\hline Rua 13 de Maio & 58 & 9 & 9 & $76 \%$ \\
\hline Rua Ademar Vicente Ferreira & 35 & 1 & 7 & $82 \%$ \\
\hline Rua 25 de Dezembro & 10 & 3 & 0 & $77 \%$ \\
\hline Rua 15 de Novembro & 30 & 2 & 6 & $79 \%$ \\
\hline Rua das Mangueiras & 35 & 2 & 0 & $95 \%$ \\
\hline Rua Sadooc Corrêa & 17 & - & 3 & $85 \%$ \\
\hline Rua Dezenove de Novembro & 14 & - & 1 & $93 \%$ \\
\hline Av. Presidente Castelo Branco & 6 & 2 & - & $75 \%$ \\
\hline Rua Dom Orione & 7 & 1 & 1 & $78 \%$ \\
\hline Rua Zico Monteiro & 11 & 0 & 6 & $65 \% \mathrm{i}$ \\
\hline Rua Floriano Machado & 9 & 3 & 0 & $75 \%$ \\
\hline Rua Gaúcho & 5 & 0 & 0 & $100 \%$ \\
\hline Rua 7 de Setembro & 8 & 0 & 3 & $73 \%$ \\
\hline Total & 513 & 46 & 59 & - \\
\hline
\end{tabular}

Fonte: Google Earth (2012), i. a rua foi inserida por estar entre outras ruas que atingiram o percentual de 70\%, o que cartograficamente tornaria inviável sua exclusão. Essa rua se apresenta como um enclave do centro, com casas herdadas de outro período histórico. 
No centro de Araguaína encontra-se uma variedade ampla de serviços e produtos encontrados em hospitais, clínicas, laboratórios, lojas de roupas (simples e de marcas), farmácias, restaurantes, relojoarias, cartórios, escritórios de advocacia e contabilidade, serviços administrativos (prefeitura e câmara dos vereadores), judiciário, instituições de crédito e seguro, óticas, perfumarias, camelódromo, cabeleireiros e serviços de estética, agências bancárias e caixas eletrônicos, lojas de eletrodomésticos, supermercados, galeria com cinema, hotéis, lojas de móveis novos e usados, materiais para construção, igrejas ${ }^{5}$, praças, etc.

Os papéis e funções do centro são fortalecidos pela convergência das principais avenidas da cidade em sua direção, como a Av. Castelo Branco, que liga diversos setores à norte da cidade; Av. Neblina, ligando a parte sudoeste e os fluxos que passam pela rodovia TO-222; Av. Prefeito João de Souza Lima, que direciona fluxos da parte sudeste e também de trechos da TO-222. Além dessas avenidas não se pode deixar de mencionar o trecho do eixo comercial da Av. Cônego João Lima na sua parte oeste (depois do córrego Neblina), e a Av. Primeiro de Janeiro, que na parte leste cumpre a função de ligação dessa área da cidade com o centro. Somam-se a isso a confluência das linhas de transporte público, uma vez que o terminal central está localizado na Praça das Bandeiras, entre as avenidas Cônego João Lima e Primeiro de Janeiro. Destaca-se, por último, a existência de 4 pontos de táxis no centro, e 6 pontos de moto táxis (serviço muito usado em Araguaína).

Deve-se considerar que a morfologia das ruas (estreitas), aliado a esse papel de nó nos fluxos de transporte, gera lentidão no trânsito e congestionamento no centro de Araguaína. Ademais, tem-se a crescente dificuldade de encontrar lugar para estacionamento, o que leva muitos consumidores a outras escolhas locacionais que atendam suas demandas com mais comodidade, compondo mais uma justificativa para o surgimento de novas áreas com centralidade.

Adentrando as variáveis escolhidas para analisar o centro e a centralidade em Araguaína, elaboramos o mapa 1, no qual aparece a delimitação do centro e a espacialização das variáveis analisadas. Verifica-se que das 12 agências bancárias da cidade, 8 encontram-se no centro, mostrando que sua primazia em termos absolutos se comparado à outras áreas da

\footnotetext{
${ }^{5} \mathrm{~A}$ matriz da Igreja Católica está localizada em frente à Praça São Luiz Oriene. Em horários de missa, principalmente aos domingos, os fluxos de pessoas nesse local são intensos. A este respeito, Pereira (2014, p. 214), afirma que "a monumentalidade ligada à religião é um aspecto intrínseco do centro principal" de muitas cidades médias.
} 
Centro e centralidade em Araguaína: reflexão preliminares a partir dos serviços e do comércio em rede cidade é significativa. Não obstante, deve-se lembrar de que no centro estão localizadas todas as agências do Banco do Brasil e do Itaú, além de duas do Bradesco (inclusivo o Bradesco Prime), o que confere a essa área da cidade em termos qualitativos importância fulcral no segmento financeiro.

\section{Mapa 1 - Distribuição de atividades do comércio em rede e serviço na cidade de}

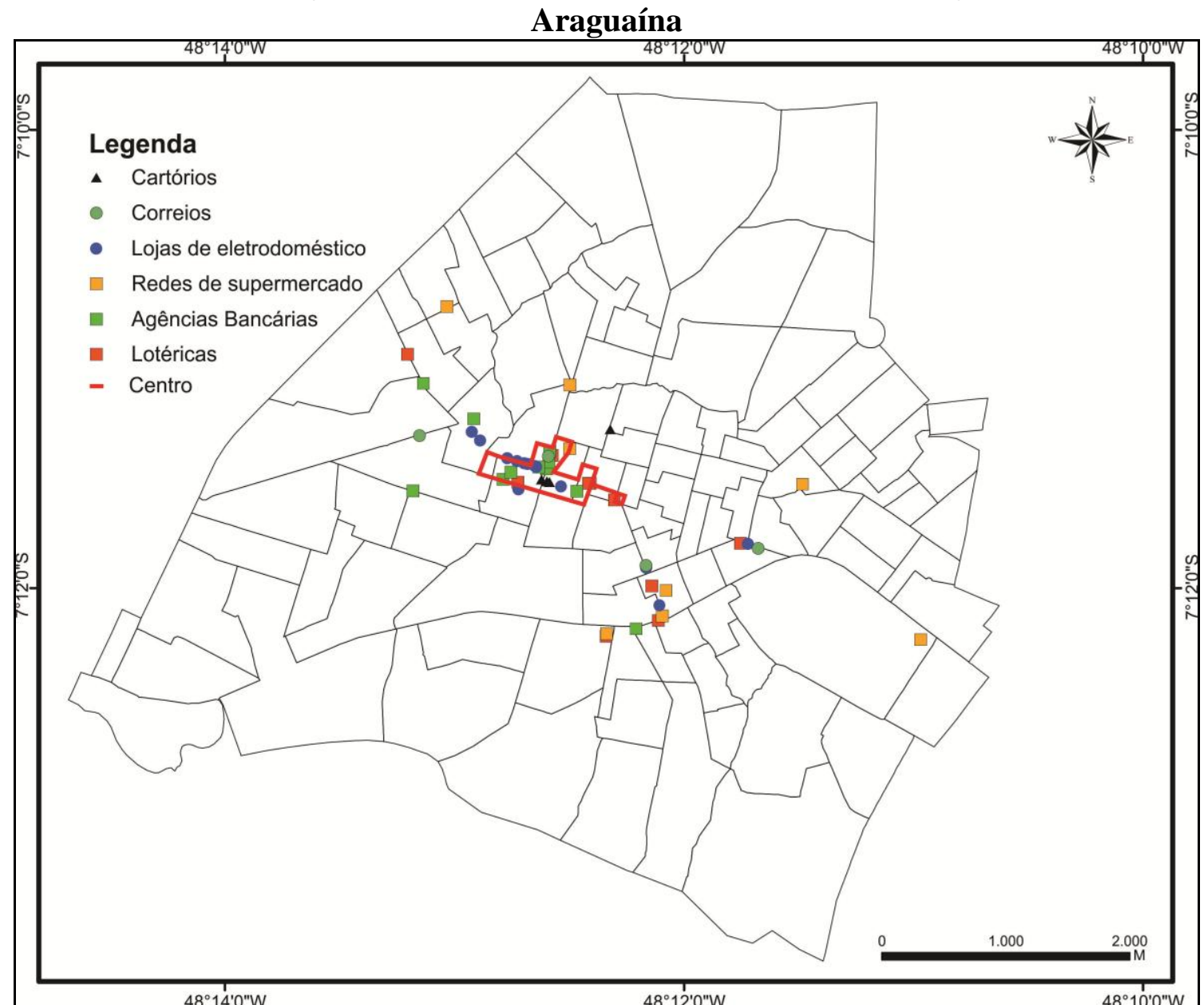

Base cartográfica adaptada do IBGE, 2010 para uma escala maior.

Fonte: Google Earth (2012). Trabalho de Campo, 2015. Elaboração: Reges Sodré (2015).

Segundo Garrocho-Rangel e Campos-Analís (2010, p. 417) os bancos não se distribuem de maneira aleatória no espaço urbano, mas segundo sítios estratégicos, que estão diretamente ligados ao reconhecimento de que "la distribución espacial de su mercado (por ejemplo, sus clientes, sus sucursales y la ssucursales de la competencia) no se distribuye de manera homogénea em el territorio". Além disso, os bancos vão se instalar em lugares que permitam a fácil acessibilidade a clientela; oferta de serviços bancários e atendimento as ambições das firmas (GARROCHO-RANGEL e CAMPOS-ANALÍS, 2010). 
Nessa perspectiva, o centro de Araguaína ainda se mostra uma posição estratégica (conforme Souza [2013], em Geografia, sítio está associado a uma concepção de espaço absoluto, enquanto posição a espaço relativo, por isso preferimos o termo posição) para a localização das atividades bancárias, ou pelo menos era de modo quase que único até o final do século XX. A partir de então, outras áreas passaram a ser atraentes, como decorrência de novas tendências de produção da cidade, expressando maior fragmentação do tecido urbano e da própria sociedade. Excetuando o Banco da Amazônia, instalado fora do centro ainda em 1973, as outras três agências bancárias localizadas fora do centro se instalaram a partir de 2007 (BRASIL, 2015), em áreas/eixos que tem apresentando forte dinamismo econômico. Incluindo-se a agência da Caixa Econômica Federal instalada no subcentro do bairro senador.

A oferta dos serviços financeiros vem se complexificando nas últimas décadas, em razão de um movimento no interior dessas atividades, mas também como manifestação de uma transformação mais ampla na própria sociedade. Aparecem novos elementos que precisam ser considerados, como os Postos de Atendimento Bancário Eletrônico (PAEs) e os Postos de Atendimento Bancário (PABs). O papel do centro na oferta desse tipo de serviço é limitado, pois dos 51 postos existentes na cidade, apenas 12 estão nele localizados (BRASIL, 2015).

A maior pulverização dos PAEs e PABs ocorre pela facilidade de localização que os mesmos usufruem, prescindindo de uma estrutura própria em favor de instalações em supermercado, industrias, postos de gasolina, estabelecimentos públicos, de ensino, hospital, etc. No caso dos supermercados terem esses serviços, fomenta até mesmo à atração de clientes, que além de fazer transações simples, aproveitam a oportunidade e consumem nesses locais.

Ainda em relação aos postos de atendimento de Araguaína, é relevante notar que esses serviços (dado que são oferecidos em quantidade pequena em cada ponto) nem sempre funcionam, é recorrente a falta de dinheiro, manutenção nos aparelhos, notas de dinheiro em poucos valores e alguns serviços não disponíveis, como depósitos, (TRABALHO DE CAMPO, 2015).

Além dos PAEs e PABs é necessário lembrar dos diversos aplicativos desenvolvidos pelos bancos para uso nos smartfones, tablets e computadores de uso pessoal, que permitem a resolução de diversas demandas, sem que a pessoa necessite sair de casa. No conjunto, esses serviços e os postos de atendimento evitam muitas viagens ao centro, 
relativizando a centralidade e o centro sob o prisma da atividade financeira. $\mathrm{O}$ uso dos aplicativos são extremamente segmentados, pois envolvem além do acesso (econômico) e o conhecimento (capacidade de manipulação) dessas ferramentas, questões de cunho subjetivo, como confiança, medos, gostos e outros fatores (PEREIRA, 2014; SPOSITO, 2001; TRABALHO DE CAMPO, 2015).

No tocante as lotéricas, constatou-se 9 unidade na cidade, das quais 4 estão presentes no centro. Esse serviço tem se deslocado nos últimos anos para os eixos comerciais, ainda que o centro seja a área da cidade com maior número de lotéricas, ele deixou de ser primaz. Além do centro, as lotéricas formam um padrão de concentração no centro-sul da cidade, no subcentro do bairro Senador, com três unidades (ver mapa 1).

Em relação aos correios, existem 4 agências na cidade e apenas uma delas está localizada no centro. A última agência foi inaugurada em abril de 2015 no Bairro São João, mostrando a emergência de novas áreas com centralidade em relação a essa atividade. Todavia, cabe ressaltar que a agência do centro oferece o serviço de Banco Postal, que nenhuma das outras agências o fazem, reforçando a centralidade dessa área em termos qualitativos.

Já os cartórios têm localização extremamente concentrada, com 3 unidades localizadas na Av. Primeiro de Janeiro (Cartório do $1^{\circ}$ oficio de notas de Araguaína; Cartório de Registro de Imóveis de Araguaína; Cartório do $2^{\text {o }}$ oficio de notas de Araguaína) e somente 1 localizada fora do centro, na rua Santa Cruz (Cartório de Registro Civil de Araguaína). Nota-se que os serviços mais usados e imprescindíveis para pessoas físicas e jurídicas são oferecidos apenas pelos cartórios do centro, já que o localizado alhures se limita a registros civis. Uma prova disso pode ser vista na arrecadação, enquanto os cartórios do centro arrecadaram em 2014 em média 1,3 milhões cada, o "periférico", atingiu um pouco mais de 100 mil (TRABALHO DE CAMPO, 2015; CNJ, 2015).

Quanto as empresas que atuam em rede no segmento dos supermercados e atacados, existem em Araguaína 3 empresas - Campelo, Atacadão e Baratão - as quais têm 8 unidades de atendimento. A Rede Campelo possui 3 supermercado na cidade, localizados em diferentes áreas, o primeiro de 1993 está situado no setor Dom Oriente, o segundo criado em 2007 no Setor Central e, o terceiro em 2008 no subcentro do setor Senador (Trabalho de Campo; Site da Empresa). Além dos supermercados a rede criou em 2011 um atacarejo localizado as margens da rodovia TO-222, também no subcentro. O Supermercado Baratão 
SODRE, R.

Centro e centralidade em Araguaína: reflexão preliminares a partir dos serviços e do comércio em rede

possui 3 estabelecimentos, sendo 2 supermercados e 1 atacarejo, localizados respectivamente nos setores Noroeste, São João, Araguaína Sul. Complementa esse segmento econômico o Atacadão do Grupo Carrefour que se instalou na cidade em 2015, com localização na TO-222 (ver mapa 1).

Essas redes de supermercado, tal como as conhecemos hoje, são uma realidade nova em Araguaína, apesar de estarem no mercado local a mais de 15 anos, Baratão e Campelo se consolidaram nos últimos 7 anos, com a criação de várias unidades pela cidade. Essas redes oferecem num mesmo local uma maior complexidade de serviços (principalmente o Campelo), agregando em seus estabelecimentos caixas eletrônicos, lotérica, franquias de roupas e de perfumes, como o boticário, farmácias, revistaria, restaurante, padarias, etc. Possuem cartões de compra para seus clientes e vendem serviços a preços diferenciados, como ingressos para o Cinema. Logram de estacionamentos próprios; segurança privada e de ambiente climatizado. Essas condições, que lembram de longe os shoppings centers, os levam a ter grande aceitação na cidade e exercer notável atração sobre extensa área do tecido urbano (a influência desses estabelecimentos também ocorre em nível regional).

Como era de se esperar o centro não tem participação importante nesse segmento. Apenas uma loja do grupo Campelo se localiza nas "bordas" do centro. Tais equipamentos precisam de grandes superfícies e de vias de trânsito rápido, coisas que o centro não mais oferece. A avenida Filadélfia (trecho da rodovia 222) tende a ser o local que vai concentrar os principais estabelecimentos desse ramo, já que conta atualmente com três grandes varejistas e atacadistas.

Em relação às redes de eletrodomésticos, foi possível identificar 7 lojas, sendo as Lojas Nosso, Liliani, Novo Mundo, Casas Bahia, Larissa Móveis, Lojas Americanas e a City Lar. Apenas as lojas Americanas não estão localizadas no centro, juntando-se a um estabelecimento da loja City Lar. Essa constatação é apenas estática, sendo necessário ir além dela, o que pressupõe uma mínima reconstituição da cronologia de instalação dessas lojas. Nesse sentido, verifica-se uma expansão a partir de 2008, quando chegam às lojas Novo Mundo e em 2013 as lojas Nosso Lar fizeram uma nova inauguração de sua planta, que atinge um pouco mais de $7000 \mathrm{~m}^{2}$ e no ano seguinte instala-se as Casas Bahia, todas localizadas no centro. Somente as Lojas Americanas inauguradas em 2011 e 2014 instalaram-se fora dessa área (Site das Lojas, trabalho de campo, 2015). 
As lojas Leolar, com sede em Marabá, se instalaram no centro de Araguaína em 2008, e fecharam seu estabelecimento em 2015. Esse fator indica a perda da concorrência para as "conceituadas" lojas Nosso Lar e Casas Bahia. Essas duas lojas são aquelas do ramo que mais movimento apresentam em seus estabelecimentos. As lojas Nosso Lar, de origem local, atua em 11 cidades e quatro estados, além de ter expandido seu capital nos últimos anos para os ramos de alimentação e distribuição de peças.

Assim, além de concentrar a maior parte das lojas no segmento de eletrodoméstico o centro tem tido sua centralidade reforçada, pois a maioria das escolhas locacionais dessas lojas o possui como destino preferido, mas não exclusivo. Essas grandes lojas compram terrenos onde outras de pequeno porte estavam instaladas, demonstrando que o preço da terra no centro, embora seja alto, ainda se mostra viável para novos investimentos, pelo retorno que a loja pode ter nessa localização, se comparado a outras áreas com preço menores.

Segundo Pereira (2014, p. 126) "a redefinição da centralidade no espaço urbano, bem como as alterações das formas e dos conteúdos do centro e da periferia nas cidades, faz parte do processo de reestruturação" já que o "surgimento de novas áreas de concentração de comércio e serviços [...] acabam por alterar as lógicas de estruturação da cidade que até então estavam postas".

Tendo isso em mente e os dados analisados, aponta-se dois processos em Araguaína que são a princípio contraditórios: de um lado, o centro tornou-se mais complexo, pela maior oferta de bens e serviços que oferece, inclusive por meio da atuação de capitais de origem nacional, por outro lado, ele deixa de ser a área procurada de forma exclusiva no tocante ao consumo de diversos bens e serviços, emergindo novas áreas com centralidade. Entendemos que esse quadro indica uma reestruturação da cidade fortalecida pelo surgimento de novas centralidades.

As novas centralidades surgem, de um lado, para atender as áreas da cidade que estão cada vez mais distantes do centro, diante da notável expansão do tecido urbano de Araguaína nos últimos 30 anos, de outro, para satisfazer as demandas da classe média. No setor Costa Esmeralda (criado em 2010) localizado a $9 \mathrm{~km}$ do centro, começa a ter uma rua comercial localizada na Av. Palmas, contando com 3 supermercado, 2 farmácias, lojas de material de construção, consultório odontológico e salão de beleza. Outra área que já expressa centralidade ligada a expansão urbana é a avenida Perimetral Oeste, que corta o Setor 
SODRE, R.

Centro e centralidade em Araguaína: reflexão preliminares a partir dos serviços e do comércio em rede

Maracanã (criado em 1981) e a Vila Couto Magalhães (criado em 1980) ${ }^{6}$. Essa avenida conta com supermercados, farmácias, posto de combustível, lojas de roupas, entre outros estabelecimentos.

Além disso, destaca-se que o subcentro da avenida prefeito João de Souza Lima se consolida com a instalação de uma agência bancária da Caixa Econômica Federal, duas unidades da rede Campelo e das Lojas Americanas, tendo em menor proporção todos os serviços oferecidos pelo centro principal. Tal subcentro está voltado para um público de baixo poder aquisitivo.

Ressalta-se ainda que a avenida José de Brito vem se tornando a cada dia uma rua especializada em consumo para um público de maior poder aquisitivo - a classe média de Araguaína. Nessa avenida estão, para citar alguns exemplos, as principais grifes de roupas, bons restaurantes, óticas de atuação nacional e salões de beleza de alto padrão. Nesse sentido, mesmo que o centro tenha recebido lojas de renome, e ampliando a quantidade de oferta, volta-se mais a um público com menor poder aquisitivo, enquanto que para a classe média surgem espaços com caráter mais segregado.

\section{CONSIDERAÇÕES FINAIS}

As transformações na estrutura urbana de Araguaína vistas a partir da centralidade condizem com uma reestruturação da cidade, pois as permanências frente às mudanças não são tão predominantes. Se por um lado, é verdade que o centro tornou-se mais complexo, pela maior oferta de bens e serviços que passou a oferecer, inclusive por meio da atuação de capitais de origem nacional, por outro lado, ele deixa de ser a área procurada de forma exclusiva pela população, em vista do surgimento de novos pontos de consumo.

Os fluxos para consumo foram parcialmente redefinidos, pois, importantes serviços se encontram relativamente pulverizados pela cidade, como correios, agências bancárias, lotéricas, redes de eletrodomésticos, Postos de Atendimento Bancário Eletrônico (PAEs), Postos de Atendimento Bancário (PABs) e redes de atacarejo/ supermercado. Os que apresentam-se menos susceptíveis a descentralização são os cartórios.

\footnotetext{
${ }^{6}$ As informações sobre a data dos loteamentos foram retiradas de Vasconcelos Filho (2013).
} 
O surgimento de uma área com concentração comercial ao longo da Av. Prefeito João de Souza Lima e parte da Av. Filadélfia se configura como um subcentro, já que praticamente todos os bens e serviços do centro principal aí estão localizados, em menor proporção e complexidade. Para citar alguns exemplos, nessa área se localiza agência bancária da Caixa Econômica, redes de eletrodomésticos, representado na unidade da Novo Mundo e outra das Lojas Americanas.

Igualmente surgem pontos mais distantes, em ruas comerciais, nos bairros como Costa Esmeralda e Setor Maracanã, que atendem a população local e dos setores vizinhos. Além disso, nota-se que a Avenida José de Brito vem concentrando a oferta de produtos e serviços para um público mais elitizado - a classe média de Araguaína.

A análise realizada necessita de aprofundamento, notadamente no que tange a investigação das práticas espaciais dos citadinos em relação ao centro e as novas áreas que emergem com centralidade. Certamente uma pesquisa nessa direção revelará resultados mais profundos e, inclusive uma estruturação a partir de tais práticas, diferente da que se encontrou nesse trabalho. É razoável também um estudo detalhado das avenidas Prefeito João de Souza Lima e seu entorno, Avenida José de Brito e nas ruas comerciais do setor Costa Esmeralda e Maracanã, visando oferecer elementos que qualifique a centralidades desses espaços, cujos serviços instalados visam públicos dispares.

\section{AGRADECIMENTOS}

À Coordenação de Aperfeiçoamento de Pessoal de Nível Superior, CAPES pela concessão de bolsas para o desenvolvimento desta pesquisa. À professora Miriam Conceição Souza pela colaboração na coleta dos dados.

\section{REFERÊNCIAS}

BRASIL, Atlas do Desenvolvimento Humano. Araguaína: caracterização do território. ca. 2013

BRASIL, Banco Central. Relação de Agências e postos bancários 2015. Disponível em: < http://www.bcb.gov.br/pt-br/paginas/default.aspx > acesso em 07/09/2015. 
CNJ - Conselho Nacional de Justiça. Justiça Aberta, 2015. Disponível em:

CORRÊA, Roberto Lobato. Processos espaciais e a cidade. Revista Brasileira de Geografia, Rio de Janeiro, ano 41, n. 3, p. 100-110, 1979.

CASTELLS, Manuel. A questão urbana. São Paulo: Paz e Terra, 2014.

GARROCHO-RANGEL, Carlos Félix.; CAMPOS-ALANÍS, Juan. Organización espacial del sistema bancario dentro de la ciudad: estrategia territorial, accesibilidad y factores de localización. Economía, sociedad y territorio, Toluca, v. 10, n. 33, p. 413-453, 2010.

LEFEBVRE, Henry. A revolução urbana. Belo Horizonte: Editora da UFMG, 1999.

MURPHY, Raymond E.; VANCE, James E. Jr. Delimiting the CBD. Readings in Urban Geography. MAYER, R.; KOHN, C (eds). Chicago: University of Chigago Press, 1954. p. 418-446.

MELO, Nágela Aparecida de. Pequenas cidades da microrregião geográfica de Catalão (GO): análises de seus conteúdos e considerações teórico-metodológicas. 527. Tese (Doutorado em Geografia) - Programa de Pós-Graduação em Geografia, UFU, Uberlândia, 2008.

PEREIRA, Cláudio Smalley Soares. Centro, centralidade e cidade média: o papel do comércio e serviço na reestruturação da cidade de Juazeiro do Norte/CE. 2014. 329 f. Dissertação (Mestrado em Geografia) - Faculdade de Ciência e Tecnologia, UNESP, Presidente Prudente, 2014.

RIBEIRO FILHO, Vitor. A Configuração da Área Central de Manaus e sua Dinâmica Recente. 2004. 246 f. Tese (Doutorado em Geografia) - Programa de Pós-Graduação em Geografia, UFRJ, Rio de Janeiro, 2001.

RAIS, Relação Anual de Informações Sociais. Vínculos Tocantins, 1990, 2010, 2014. ca. 2015

TOURINHO, Andréa de Oliveira. Centro e centralidade: uma questão recente. In: Oliveira, Ariovaldo Umbelino de.; CARLOS, Ana Fani Alessandri. Geografia das metrópoles. São Paulo: Contexto, 2006. pp. 277-299.

SOUZA, Marcelo Lopes de. Os conceitos fundamentais da pesquisa sócio-espacial. Rio de Janeiro: Bertrand Brasil, 2013.

SPOSITO, Maria Encarnação Beltrão. O centro e as formas de expressão da centralidade urbana. Revista geografia, São Paulo, v. 10, p. 1-18, 1991.

. Centros e centralidades no Brasil. FERNANDES, José Alberto Rio.; SPOSITO, Maria Encarnação Beltrão. A nova vida do velho centro nas cidades portuguesas e brasileiras. Porto, CEGOT, 2013. p. 45-59. 
Centro e centralidade em Araguaína: reflexão preliminares a partir dos serviços e do comércio em rede

WHITACKER, Arthur Magon. Centralidade intraurbana e morfologia em cidades médias: transformações e permanências. In: XI seminário internacional Red Iberoamericana de investigadores sobre globalización y territorio; Red Iberoamericana de editores de revista. Argentina: Mendoza, 2010. n.p.

VASCONCELO FILHO, João Manuel de. O direito à moradia e o discurso de implantação de políticas públicas habitacionais na perspectiva de construção de cidades saudáveis e democráticas: reflexões sobre a Araguaína-TO. 2013. 220 f. Tese (Doutorado em Geografia) - Programa de Pós-Graduação em Geografia, UFU, Uberlândia, 2013.

\section{Autor}

Reges Sodré - Possui Graduação em Geografia pela Universidade Federal do Tocantins (UFT) e Mestrado em Geografia pela Universidade Federal de Uberlândia (UFU). Atualmente é Professor na Rede Estadual de Educação do Estado do Tocantins.

Artigo recebido em: 23 de novembro de 2016.

Artigo aceito em: 22 de abril de 2017. 